\section{Holocene book review}

\author{
Sarah E Metcalfe and David J Nash (editors) \\ Quaternary Environmental Change in the Tropics \\ Chichester:Wiley-Blackwell, 2012, 436 pp. \\ $£ 55.00 / € 66.20$, hardback. ISBN 978-I-I I8-34325-8
}

\section{Reviewed by: Klaus Heine, University of Regensburg, Germany}

'Climate change in different parts of the tropics is far more complex than scientists of the last century ever could have envisaged' (p. 10). Consequently, this volume, Quaternary Environmental Change in the Tropics, is overdue. The objective of the volume is 'to synthesize understanding of how tropical environments have changed over the past 2.6 million years' (p. xiii). It is intended for final-year undergraduates and research specialists, yet readers of related disciplines may also find it informative. The editors express the hope that 'the publication will provide an indispensable background for future regional and global research of tropical Quaternary environments'.

Eighteen distinguished authors address a range of carefully selected topics comprising: (1) the evidence for environmental change with reference to existing sedimentological, geochemical, biological, geomorphological and archaeological data covering the whole of the Quaternary, (2) spatial (e.g. Northern versus Southern Hemisphere) and temporal (e.g. glacial versus interglacial) variability within and between regional records, and (3) driving forces of environmental changes (e.g. climatic versus human-induced mechanisms). The main focus of the volume is a discussion of tropical and subtropical landmasses and islands. Because terrestrial records for the Early and Middle Pleistocene are rare, marine records are important sources for reconstructions of the pre-Eemian continental tropics. Depending on the authors' individual research activities, regions and subjects are dealt with in various ways despite the request to focus on a number of specific issues.

The text details the Quaternary of the tropics in a readable style covering all major issues in 11 chapters distributed in three sections: (I) Global contexts, (II) Regional environmental change, and (III) Global syntheses.

Global contexts (I): Chapter 1 (Introduction), written by Metcalfe and Nash, tells the reader why the tropics matter, how the ideas about tropical environmental change developed, what the drivers of tropical environmental change are, why the tropics cause environmental changes, and why extra-tropical forcing should be considered. This chapter unveils all the complex and intricate linkages between processes in the tropics and subtropics as caused by variations in incoming solar radiation, the ENSO tele-connections, the long-lived greenhouse gases and aerosols, and volcanic ashes and dust emissions, among others. The introduction is crucial for understanding Quaternary global change in the tropics. Chapter 1, however, does not present a clear definition of the tropics, neither in the text nor in Figure 1.3 (or colour plate 2). In the text, 'tropics' and 'subtropics' are used as terms to delineate the Earth's regions of concern, and greenhouse gas concentrations are only mentioned for the Holocene. In Chapter 2, Hastenrath presents a brief introductory overview of the contemporary climate and circulation patterns in the tropics.

Regional environmental change (II): this section comprises six chapters (3 to 8). In Chapter 3, Stuut, Prange, Merkel, and Steph portray the tropical oceans in the global climate system and review the methods and evidence for environmental changes throughout the Quaternary. With respect to the Holocene, the growing evidence for obvious changes in the amplitude and frequency of ENSO is discussed. In Chapter 4, Nash and Meadows summarize the information for Africa. The authors divide the continent into four areas: the Mediterranean North Africa, the Sahara and the Sahel, equatorial Africa, and southern Africa, and include also the extra-tropical Mediterranean and South African winter rainfall regions. Yet, for the understanding of Quaternary climatic changes the incorporation of these regions is absolutely necessary. While the Quaternary of the southern monsoonal domain, of equatorial and subequatorial East Africa and of the southern Saharan and Sahelian domains provides good data, almost nothing is known about the Congo Basin, Angola, Zambia, and Mozambique. Nevertheless, the data illustrate that the African tropical rainforest has expanded and contracted symmetrically in response to Quaternary changes in climate (p. 129). For every region, the Holocene is considered separately, including the detailed record of climatic fluctuations for East Africa, and discussions as to whether landscape and vegetation changes in the Mediterranean are a consequence of climate change and/or human activity, and whether the Sahara experienced a gradual change from 'humid' conditions to hyperaridity. In Chapter 5, Singhvi, Bhatt, Glennie and Srivastava review India, Arabia and adjacent regions. Again, different areas are discussed one by one (India and Tibet, Arabian Sea and Bay of Bengal, Arabia and the Middle East). The discussion includes the Himalayas and Tibet and emphasizes that Tibet was never totally covered with ice as suggested in past studies. Information about environmental changes during the Holocene is scattered and mainly relates to Himalayan and Tibetan lacustrine and Indian peat, fluvial and cave records, marine records from the Arabian Sea and Persian Gulf (in great detail), and Arabian sabkha and interdune deposits. In Chapter 6, Penny reviews the environmental changes of China and Southeast Asia (Indochina, Sundaland and Wallacea). The author presents an impressive amount of data on Chinese terrestrial loess and cave sequences and the monsoon history, and their relation to orbital and radiation forcing. An abrupt transition to the Holocene is documented for Indochina. In Chapter 7, Kershaw and van der Kaars address Australia and the southwest Pacific Islands. While environmental changes of the Australian tropics are mainly based on marine pollen records from nearby seas, central Australia provides fluvial, lacustrine and aeolian palaeoclimate archives. Termination 1 and the Holocene are reviewed in some detail. In Chapter 8, Bush and Metcalfe present information on Latin America and the Caribbean based on a large number of records from many palaeoenvironmental archives. The authors conclude that no single forcing mechanism was responsible for changes in the Neotropics. Besides a detailed review of the 
Pleistocene, topics such as 'timing and pattern of Holocene climatic changes', 'the El Niño phenomenon' and 'Climate and societies' are also discussed.

Global synthesis (III): in Chapter 9, Liu and Braconnot reexamine important processes and advances in the modelling of tropical climate during the LGM and the Holocene. Although the chapter is devoted to modelling, the authors provide no information about modelling of tropical environments. Modelling studies show that 'major features of tropical climate change in the Holocene are generated, at least quantitatively, by the insolation forcing alone' (p. 321), but that climate changes in the LGM were driven mainly by the radiative forcing, although the orbital change is the most important external forcing. In Chapter 10, 'Historical environmental change', Endfield and Marks focus exclusively on the Holocene. Climate change is evoked as a factor to explain the rise and collapse of civilizations, although the reader should bear in mind that climate change does not fully explain the complex geographic and socio-political events of ancient civilizations (Mexico and China are treated in detail). In Chapter 11, 'Past and future environmental changes', Nash and Metcalfe, based on the preceding chapters, present a balanced chronological synopsis of tropical environmental changes from the last interglacial to the Holocene, a cautious analysis of climate forcings and the tropics as drivers of change, and a look at future changes with special reference to monsoon systems, ENSO events, extreme events, water resources and biodiversity.

This reviewer has some suggestions for future volumes on the subject. First, the definition of the tropics (Figures 1.2 and 1.3 and Plates 1 and 2 in Chapter 1) should delineate the limits between the tropics, subtropics and temperate zones on the basis of environmental criteria (see map of Seasonal Climates of the Earth, Troll, 1964). Maybe, a new edition of the book can be supplemented with maps showing the limits of the tropics and subtropics during MIS 5e, the LGM, and the Holocene Climatic Optimum. Second, it turned out that a big gap between modellers and palaeoenvironmentalists exists: in Chapter 9 an abrupt change from wet to dry conditions in the Sahara in the mid Holocene is modelled based on only one marine core with incomplete core recovery (pp. 343-344), although a gradual change from 'green' to desert is reported from a great number of terrestrial Saharan and Sahelian records (pp. 100-103). Third, textbooks rely on illustrations as visual supplement to the text. Some photos of characteristic environments comparable with those of the past would have been helpful, as well as illustrated reconstructions of past environments. For example: what would the early Holocene 'green' Sahara have looked like? Fourth, not adding together but evaluating different climate proxies can provide further insights (e.g. Andes versus Pacific records). Lowering of mountain permafrost belts which are strictly temperature-related provides sound evidence of temperature changes in the tropics and can be critically compared with estimates derived from geochemical proxies. Fifth, although about 2300 references are listed in total, only English written papers and books are cited, except a few historical German and French, as well as some Spanish publications. Furthermore, some very important and detailed new publications are missing. For example, Pachur and Altmann (2006), a unique compilation covering comprehensively the late Quaternary of the East Sahara, is not referred to.

Quaternary Environmental Change in the Tropics will be a highly respected textbook and an extremely valuable source for information on the tropical environmental changes during the Pleistocene and Holocene. Absolute statements are not made without critical assessment of issues that are really controversial. Above all, the book shows that - despite the enormous number of records for environmental changes in the tropics - there are many unresolved problems.

\section{References}

Pachur HJ and Altmann N (2006) Die Ostsahara im Spätquartär. Ökosystemwandel im größten hyperariden Raum der Erde. Berlin-Heidelberg: Springer.

Troll C (1964) Karte der Jahreszeitenklimate der Erde. Erdkunde 18: 5-28. 